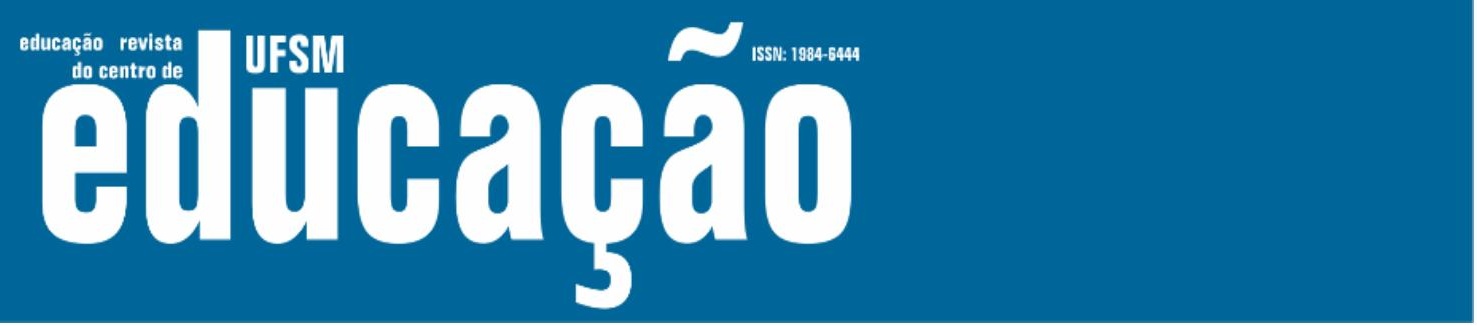

ISSN: 1984-6444 | http://dx.doi.org/10.5902/1984644443625

\title{
Os espaços de atuação profissional do licenciado em Ciências da Natureza no Brasil: um delineamento a partir da compreensão dos sistemas estaduais de ensino
}

\author{
The spaces of professional performance of the degree in Natural \\ Sciences in Brazil: an outline based on the understanding of state \\ teaching systems
}

Jéferson Pereira da Silva

Professor Mestre na Faculdade Eduvale, Jaciara, Mato Grosso, Brasil.

jefersonjuniorpereira@hotmail.com - https://orcid.org/0000-0002-5056-2023

Natália Silva Neris

Cursando especialização no Instituto Federal de Mato Grosso, Campus São Vicente, Jaciara, Mato Grosso, Brasil.

natalia.sneris@gmail.com - https://orcid.org/0000-0002-9528-0847

Marcos Vinícius Ferreira Vilela

Professor doutor na Universidade Federal de Goiás, Goiânia, Goiás, Brasil.

marcos.vilela@ufg.br - https://orcid.org/0000-0001-8437-7646

Leandro Carbo

Professor Doutor no Instituto Federal de Educação, Ciência e Tecnologia de Mato Grosso, Campus São Vicente, Mato Grosso, Brasil.

leandro.carbo@ifmt.edu.br - https://orcid.org/0000-0001-5514-7040

Recebido em 18 de agosto de 2020

Aprovado em 11 de setembro de 2020

Publicado em 31 de julho de 2021

\section{RESUMO}

Este texto discute os espaços de atuação profissional dos licenciados em Ciências Naturais/da Natureza nos sistemas estaduais de ensino do Brasil. O trabalho teve como objetivo conhecer e compreender como os sistemas estaduais de ensino, por meio de seus entendimentos legais, reconhecem e definem os espaços de atuação profissional dos licenciados em Ciências Naturais/ da Natureza. Foi realizada uma pesquisa documental, em que foram identificadas as manifestações de sete conselhos estaduais, por meio de resoluções, pareceres e outros documentos. A partir dos documentos analisados, foi possível perceber que aqueles conselhos que se pronunciaram sobre o tema estabelecem um rol de várias formações, que, segundo esses órgãos, formam profissionais aptos a lecionar a disciplina de Ciências nos anos finais do ensino fundamental. Apesar da licenciatura em Ciências Naturais/da Natureza figurar entre essas formações, parece haver uma predileção 


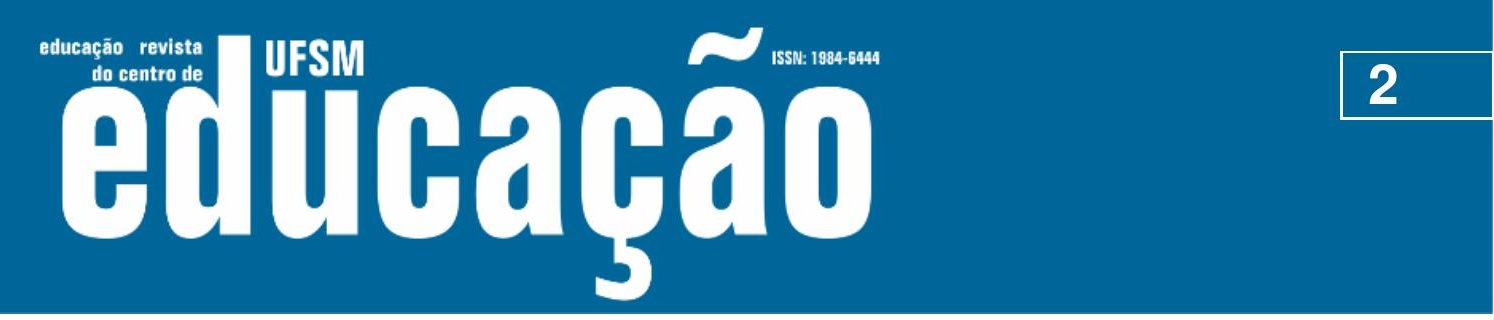

ISSN: 1984-6444 | http://dx.doi.org/10.5902/1984644443625

dos sistemas de ensino por cursos de licenciatura que formam para campos disciplinares específicos. Nessa perspectiva, eles buscam atender às suas necessidades de gestão, em detrimento das necessidades formativas da disciplina de Ciências. Por conseguinte, a prioridade dada pelos sistemas de ensino às suas demandas operacionais e 0 aparente desconhecimento destes sobre as licenciaturas em Ciências Naturais/da Natureza fazem com que os profissionais egressos desses cursos tenham dificuldades para ter o seu espaço profissional reconhecido nesses sistemas de ensino.

Palavras-chave: Formação de professores de Ciências; Sistemas estaduais de ensino; Licenciados em Ciências Naturais/da Natureza.

\section{ABSTRACT}

This text discusses the professional performance spaces of graduates in Natural / Nature Sciences in the state education systems in Brazil. The work aimed to know and also understand how the state teaching systems, through their legal understandings, recognize and define the spaces of professional performance of graduates in Natural / Nature Sciences. A documentary research was carried out, in which the manifestations of seven state councils were identified, through resolutions, opinions and other documents. From the analyzed documents, it was possible to perceive that those councils that gave their opinion on the theme establish a list of various backgrounds, which, according to these bodies, form professionals capable of teaching the discipline of sciences in the final years of elementary school. Although the degree in Natural Sciences / Nature is among these formations, there seems to be a predilection for the teaching systems for undergraduate courses they form for specific disciplinary fields. In this perspective, they seek to meet their management needs, to the detriment of the training needs of the Science discipline. Consequently, the priority given by the education systems to their operational demands and their apparent lack of knowledge about degrees in Natural / Nature Sciences make the professionals graduating from these courses have difficulties to have their professional space recognized in these education systems.

Keywords: Science teacher education; State education systems; Graduates in Natural/Nature Sciences.

\section{Introdução}

A formação de professores de Ciências no Brasil, ao longo de sua história, teve como pano de fundo uma sucessão de políticas públicas voltadas à superação do déficit quantitativo desses profissionais. Essa história começa na década de 


\section{Autนaดูลิ}

ISSN: 1984-6444 | http://dx.doi.org/10.5902/1984644443625

1930, com a criação dos cursos de História Natural. Mais adiante, na década de 1960, durante o governo militar, foram criadas as licenciaturas curtas em Ciências, cursos estes que perduraram até a entrada em vigor da LDBEN/1996 ${ }^{1}$ (BRASIL, 1996).

A partir do início do século XXI, em decorrência de políticas governamentais voltadas à modernização e à expansão do ensino superior, algumas instituições implantaram cursos de licenciatura organizados por área do conhecimento. Dentre esses, destacamos a Licenciatura em Ciências Naturais/da Natureza², que tem por finalidade formar professores para lecionar a disciplina de Ciências nos anos finais do ensino fundamental.

Importante salientar que, apesar das licenciaturas curtas em Ciências, criadas durante o regime militar, e as atuais licenciaturas em Ciências Naturais/da Natureza compartilharem a finalidade de formar professores para atuar nos anos finais do ensino fundamental (antigo ciclo ginasial), poucas são as semelhanças existentes entre elas.

Enquanto as licenciaturas curtas surgem como medida emergencial, visando suprir uma carência quantitativa de professores, as licenciaturas por área do conhecimento, também denominadas de interdisciplinares, visam formar docentes capazes de estabelecer relações entre os saberes oriundos dos campos disciplinares das Ciências da Natureza (Química, Física e Biologia). Por meio dessa formação, espera-se superar um ensino de Ciências fragmentado e descontextualizado, fazendo com que os estudantes tenham compreensão integral e crítica dos conceitos e fenômenos científicos.

Todavia, mesmo que os cursos de licenciatura em Ciências Naturais/da Natureza estejam sendo elaborados por estudiosos da área de ensino de Ciências como uma alternativa aos cursos tradicionais de formação disciplinar, o processo de consolidação dessas licenciaturas não tem sido fácil. A ausência de diretrizes e/ou referenciais curriculares específicos tem sido um obstáculo à garantia do espaço de atuação profissional para os licenciados nesses cursos. 


\section{Autharẫ}

ISSN: 1984-6444 | http://dx.doi.org/10.5902/1984644443625

Nessa perspectiva, vários são os questionamentos que surgem quanto às possibilidades de atuação desses profissionais, quais sejam: Em qual (is) nível (is) da educação básica um licenciado em Ciências Naturais/da Natureza pode atuar? No caso de só atuarem nos anos finais do ensino fundamental, quem tem prioridade para ministrar a disciplina de Ciências, o licenciado em Ciências ou o licenciado em Biologia? Com a implantação da nova Base Nacional Comum Curricular (BNCC), que organiza os componentes curriculares por área do conhecimento, tal modificação ampliará as possibilidades de atuação desses licenciados?

Diante desses e de outros questionamentos que carecem de um posicionamento oficial, acaba ficando a cargo do mercado de trabalho tomar essas decisões. Nesse segmento, sabemos que os sistemas estaduais de ensino são aqueles que apresentam maior demanda por esses profissionais.

O Art. 10 da LDBEN/1996 concede aos sistemas estaduais, dentro do limite estabelecido por lei, a prerrogativa de decidir sobre a qualificação mínima do docente apto a atuar em sua rede de ensino. No desempenho de suas atribuições consultivas, normativas e deliberativas, cabem aos Conselhos Estaduais de Educação (CEEs) assessorar as secretarias estaduais, na definição do perfil profissional adequado para atuar na educação básica. Fundamentadas nos parâmetros estabelecidos pelos CEEs, as secretarias de educação elaboram os editais de concursos e processos seletivos, visando à contratação de professores.

A partir do cenário apresentado, surge o seguinte questionamento: Qual o entendimento dos sistemas estaduais de ensino, caso existam, sobre a qualificação docente necessária para ensinar ciências nos anos finais do ensino fundamental? Nessa perspectiva, o licenciado em Ciências Naturais/da Natureza é visto como um profissional adequado para essa tarefa, tendo, assim, o seu espaço de atuação profissional reconhecido e respeitado?

Com base nessa problemática, a presente investigação teve por objetivo conhecer e também compreender como os sistemas estaduais de ensino, por meio de seus entendimentos legais, reconhecem e definem os espaços de atuação profissional dos licenciados em Ciências Naturais/ da Natureza. A partir desse objetivo de investigação, foram levantados e analisados pareceres, manifestações e 


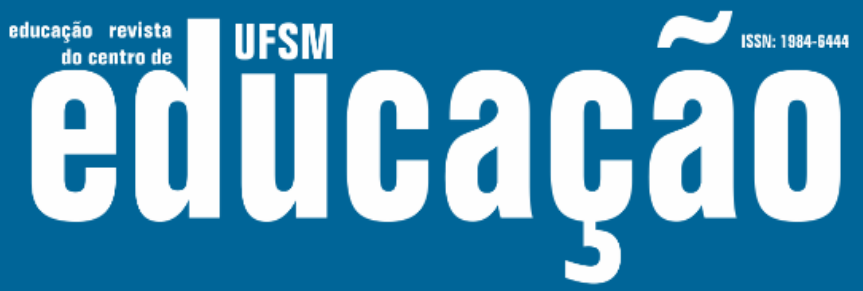

ISSN: 1984-6444 | http://dx.doi.org/10.5902/1984644443625

atos normativos dos CEEs, os quais orientam os sistemas estaduais de ensino, sobre qual a formação necessária para que o professor esteja qualificado para lecionar a disciplina de Ciências nos anos finais do ensino fundamental.

\section{Reflexões sobre o ensino de Ciências da Natureza no Brasil}

Diversos estudiosos, como Carvalho (2000), Krasilchik (2000), Nascimento, Fernandes e Mendonça (2010), Cachapuz et al. (2015), Gozzi e Rodrigues (2017), dentre outros, têm mostrado preocupação e alertado para a necessidade de melhoria do ensino de Ciências no Brasil. A partir da década de 1950, a visão da Ciência como algo objetivo, neutro e distante da realidade das pessoas começa a ser questionada, sobretudo por aqueles que passaram a discutir as consequências das relações entre Ciência, Tecnologia e Sociedade (CTS) (NASCIMENTO; FERNANDES; MENDONÇA, 2010).

A adoção de uma visão mais crítica acerca das consequências dos empreendimentos científicos e tecnológicos abriu novas possibilidades para o ensino de Ciências (AULER, 2007; SANTOS, 2011). Com a Ciência passando a ser vista como produto decorrente da ação social e humana, a consolidação dessa nova percepção depende da formação de cidadãos críticos, aptos a atuar nos processos decisórios que envolvem o tema.

A segunda metade do século $X X$ foi um período em que as concepções em torno do ensino de Ciências sofreram interferências de naturezas diversas. Se, por um lado, a ressignificação da concepção de Ciência impulsionou movimentos em prol do estudo das relações entre CTS e interdisciplinaridade, por outro, o ensino de Ciências, especialmente no Brasil, serviu a diferentes objetivos, por conta de questões políticas ocorridas nas décadas subsequentes.

Durante as décadas de 1960 e 1970, o Brasil teve as suas concepções educacionais alteradas profundamente em decorrência do Regime Militar. Nesse momento, muda-se o papel da escola, que volta os seus objetivos à formação de mão de obra, em detrimento da formação para a cidadania. Em parte, essa mudança de foco deve-se ao alinhamento entre o então governo militar brasileiro e o norte- 


\section{Althaห̧ão}

ISSN: 1984-6444 | http://dx.doi.org/10.5902/1984644443625

americano. Também nesse período, entrou em vigor a LDBEN de 1971 (Lei no $5.692 / 71)^{3}$. Dentre as mudanças instituídas por essa nova legislação, destacamos a ampliação da oferta da disciplina de "Ciências Físicas e Biológicas", que passou a ser obrigatória em todo o $1^{\circ} \mathrm{grau}$ (atual ensino fundamental).

A partir da segunda metade da década de 1970, o governo militar começa a entrar em declínio, em decorrência, sobretudo, da crise econômica que afligia o país. Nesse segmento, o fracasso do governo em promover o desenvolvimento do país em um curto espaço de tempo torna-se o combustível para o surgimento de movimentos sociais e políticos, os quais objetivava a retomada da democracia (SILVA; PEREIRA, 2011).

$\mathrm{Na}$ década de 1980, os movimentos em prol da redemocratização do país ganham força, o que culminou com o fim da ditadura militar. Com a promulgação da Constituição Cidadã (Constituição de 1988), muda-se o foco do que se espera da educação e da escola. Essa mudança de concepção reformula também os objetivos do Estado para o ensino de Ciências. Além da formação para a cidadania, havia a intenção de se retomar o interesse dos jovens pela Ciência.

De acordo com Krasilchik (2000), a constituição de um novo Estado democrático necessitava de uma sociedade que fosse cientificamente alfabetizada 4 . Em outras palavras, para esse novo modelo de país, torna-se necessário um ensino de Ciências capaz de formar cidadãos críticos e aptos para participar da tomada de decisões em temas que envolvam Ciência e Tecnologia.

Em meados da década de 1990, com a entrada em vigor da LDBEN/19965, há uma ampliação considerável das responsabilidades do poder público no que se refere à oferta de um ensino de qualidade, sobretudo para o ensino fundamental. Para esse nível de ensino, também é sugerida uma nova organização curricular, em decorrência da publicação dos Parâmetros Curriculares Nacionais (PCNs).

Esse novo currículo propôs a organização dos conteúdos e componentes curriculares, a partir de diferentes áreas do conhecimento, entre elas, as Ciências Naturais. Nessa perspectiva, os conteúdos abordados na disciplina de Ciências estruturaram-se a partir de quatro blocos temáticos: Terra e Universo; Vida e Ambiente; Ser Humano e Saúde e; Tecnologia e Sociedade (BRASIL, 1998). 


\section{Authab̧ão}

ISSN: 1984-6444 | http://dx.doi.org/10.5902/1984644443625

Todavia, na prática, o que ocorreu foi a distribuição linear e isolada desses blocos do conhecimento. Os livros didáticos e, por consequência, as escolas passaram a abordar blocos inteiros, em cada um dos anos finais do ensino fundamental. Conteúdos que abordavam os saberes de física e química, por exemplo, eram ensinados de forma isolada no $9^{\circ}$ ano do ensino fundamental.

Os PCNs, apesar de não terem um caráter de obrigatoriedade, influenciaram a concepção dos currículos das redes estaduais e municipais de todo o Brasil. No entanto, essas orientações curriculares foram recentemente substituídas por uma Base Nacional Comum Curricular (BNCC ${ }^{6}$ ). Ao contrário do que ocorria com os PCNs, a adoção da BNCC é obrigatória, devendo ser a referência nacional para a elaboração dos currículos de todos os sistemas de ensino ${ }^{7}$ (BRASIL, 2017).

Para a disciplina de Ciências, a BNCC manteve muito dos pressupostos já previstos nos PCNs. No entanto, substituiu o que conhecíamos como eixos temáticos pela denominação unidades temáticas, que passaram a abordar os seguintes temas: matéria e energia, vida e evolução e Terra e universo. Outra mudança importante foi a definição de que essas unidades de conteúdo não deveriam mais ser ensinadas em um ano específico, como ocorria nos PCNs.

Nessa perspectiva, os objetos do conhecimento ${ }^{8}$ que compõem as unidades temáticas estão distribuídos ao longo de todos os anos finais do ensino fundamental. Com essa organização do currículo em espiral, espera-se que os alunos consigam ter melhor compreensão do conteúdo, acompanhando gradativamente a construção dos conceitos, atingindo, assim, a literacia científica (BRASIL, 2017).

Todavia, a implantação da BNCC tem recebido diversas críticas de pesquisadores e entidades educacionais. Dentre as ressalvas apresentadas, destacamos o receio de que a adoção de uma base comum possa promover uma homogeneização perigosa dos sistemas escolares, em que seriam desconsideradas as diversidades locais (FRANCO; MUNFORD, 2018).

Para o ensino de Ciências, questiona-se a ênfase excessiva nos aspectos conceituais e a codificação das habilidades a serem desenvolvidas. Esse último aspecto sugere o alinhamento da BNCC aos interesses do mercado educacional. Importante dizer que esses e outros questionamentos denotam o distanciamento do 


\section{Autนaดูลิ}

ISSN: 1984-6444 | http://dx.doi.org/10.5902/1984644443625

que propõe a BNCC em relação às discussões mais atuais no campo da educação em Ciências (FRANCO; MUNFORD, 2018).

Ao que parece, assim como ocorreu com os PCNs, a implementação da BNCC almeja facilitar a gestão dos sistemas de ensino, deixando as necessidades pedagógicas em segundo plano. Aparentemente também não foram consideradas as necessidades de melhorias na infraestrutura das escolas e na formação de professores.

Nessa perspectiva, Tenfen (2016) alerta que a implementação da nova base necessitará de uma modificação nos programas de formação de professores de Ciências. Ainda segundo a autora, a implementação da BNCC precisará de que os professores dominem os saberes históricos e epistemológicos, superem possíveis concepções distorcidas de Ciência e estejam aptos a planejar e a executar ações pedagógicas que sejam condizentes com os pressupostos do documento.

\section{Formação inicial de professores para ensinar Ciências no ensino fundamental}

Magalhães Júnior e Pietrocola (2005, p. 01) explicitam que "a história do ensino de ciências no Ensino Fundamental no país é muito recente, e o que se percebe é que a formação de professores desse nível de ensino, hoje, ainda se apresenta pouco assumida pelas universidades brasileiras". Esse cenário atual descrito pelos autores coaduna com a história de formação de professores de Ciências no Brasil.

Somente a partir da década de 1930, surgem as primeiras Faculdades de Filosofia, Ciências e Letras, instituições que formavam professores em nível superior. No que tange à formação de professores de Ciências, o primeiro curso superior criado no Brasil com esse objetivo foi implantado pela Faculdade de Filosofia de São Paulo, em 1934, sendo denominado de História Natural (ULIANA, 2012).

Todavia, eram poucos os cursos de História Natural existentes no Brasil e, além disso, a sua formação era mais voltada ao bacharelado do que à licenciatura. 


\section{Authaดูã}

ISSN: 1984-6444 | http://dx.doi.org/10.5902/1984644443625

Dessa forma, mantinha-se o déficit quantitativo e qualitativo na formação dos professores de Ciências. Essa incapacidade das instituições em atender à demanda de formação de professores de Ciências e de outras áreas passou a ser vista como um dos principais obstáculos na luta pela garantia do acesso universal a uma educação de qualidade.

A extinção do curso de História Natural veio ocorrer três décadas depois da sua criação, no ano de 1963. O seu fim deu-se por conta do pequeno número de vagas ofertadas, fazendo com que este curso não conseguisse atender à demanda de formação, em termos quantitativos. Acrescenta-se a isso a decisão do $\mathrm{CFE}^{9}$ pelo seu desdobramento, visando à criação dos cursos de Ciências Biológicas e Geologia. Essa divisão foi motivada, sobretudo, pela necessidade da oferta de um curso voltado à formação de geólogos, profissão que já havia sido regulamentada (ULIANA, 2012).

Por conta de uma maior afinidade do curso de Ciências Biológicas com os conteúdos ensinados nas disciplinas de Ciências, os profissionais formados nesse curso acabaram por herdar a prerrogativa de ensinar essa disciplina no ensino fundamental. Fato que perdura até os dias de hoje. Contudo, o déficit de professores com formação para ensinar Ciências persistia, o que levou o então governo militar a promover reformas na educação superior.

Dentre as medidas propostas, destacamos a criação das licenciaturas curtas (LC), em 1964, a partir da indicação do CFE, consubstanciada no parecer do conselheiro Newton Sucupira. Essas licenciaturas foram criadas em caráter emergencial e experimental, visando a reverter o déficit de professores em diversas áreas e regiões do país. Em seu parecer, o conselheiro também reconhece a área de Ciências da Natureza e Matemática como a mais carente em termos de formação docente (NASCIMENTO, 2012).

A efetivação das licenciaturas curtas em Ciências ocorreu por meio da Lei n. 5.540/68 (instituiu a reforma universitária) e, mais tarde, pela Lei $n . .05 .692 / 1971$ (instituiu a reforma no ensino de $1^{\circ}$ e $2^{\circ}$ graus). Esses cursos, com duração menor do que as licenciaturas plenas, tinham como objetivo formar professores polivalentes, que iriam atuar nas disciplinas de Ciências Físicas e Biológicas e/ou 


\section{Nusm Eitloab̧a}

ISSN: 1984-6444 | http://dx.doi.org/10.5902/1984644443625

em quaisquer outros componentes com temas correlatos, limitados à atuação nas séries que compunham o $1^{\circ}$ grau (FERREIRA, 1983).

Entretanto, o que parecia ser uma medida emergencial acabou tendo um caráter permanente, perdurando até meados da década de 1990. A extinção destes cursos deu-se apenas no ano de 1996, com a entrada em vigor da LDBEN/1996. Por conta da nova legislação, cabia às instituições formadoras decidirem sobre o que fazer com as licenciaturas curtas em Ciências.

As IES ofertantes dessas licenciaturas, em sua maioria, optaram pela sua plenificação em um dos campos disciplinares das Ciências da Natureza (Biologia, Química e Física). Outras instituições formadoras, como a Universidade Federal do Amazonas (UFAM), adequaram-se ao disposto na LDBEN/1996, mantendo, entretanto, um perfil de curso voltado à formação de professores para ministrarem a disciplina de Ciências nos anos finais do ensino fundamental (VILELA, 2018).

No início do século XXI, o Brasil iniciou um processo expressivo de ampliação da oferta de vagas na educação superior. Programas como o REUNI ${ }^{10}$ e a criação dos Institutos Federais promoveram a ampliação da oferta de cursos de licenciatura, sobretudo para aquelas áreas com maior déficit de professores. Também foi incentivada a criação de cursos que buscassem a inovação de seus currículos, com ênfase em propostas de formação interdisciplinares.

Nesse movimento, surgem as licenciaturas por área de conhecimento, também denominadas de interdisciplinares, nas quais os licenciandos estudam temas amplos e diversificados e a formação ocorre por área do conhecimento (BIERHALZ; ARAÚJO; LIMA, 2013).

Os cursos de licenciatura em Ciências Naturais/da Natureza têm como objetivo formar professores para atuar nos anos finais do ensino fundamental. Como conteúdos obrigatórios, o acadêmico cursa disciplinas pedagógicas e também disciplinas relacionadas com diversas áreas das Ciências da Natureza, tais como: Física, Biologia, Química, Geologia, Astronomia, Meteorologia e Paleontologia, além de disciplinas na área de Matemática (IMBERNON et al., 2011).

Neste momento, é importante pontuar que, apesar da aparente semelhança entre as licenciaturas interdisciplinares e licenciaturas curtas, entendemos que os 


\section{Hism

ISSN: 1984-6444 | http://dx.doi.org/10.5902/1984644443625

seus objetivos de formação são diferentes. Enquanto que as licenciaturas curtas foram criadas para atender precariamente a uma demanda emergente de professores para a educação básica, as licenciaturas interdisciplinares buscam formar professores capazes de ensinar Ciências de uma forma integrada, de forma a estarem aptos a trabalhar com metodologias e/ou técnicas interdisciplinares (MAGALHÃES JÚNIOR; PIETROCOLA, 2005, 2010).

Apesar do avanço das discussões e de pesquisas acerca do ensino e da formação de professores de Ciências, o que parece perdurar, desde as licenciaturas curtas até os dias de hoje, é a controvérsia em torno do perfil do professor qualificado a ensinar Ciências no ensino fundamental. Do ponto de vista pedagógico, parece não haver dúvidas de que uma formação interdisciplinar, por área do conhecimento, tem melhores condições de formar um professor capaz de superar um ensino de Ciências fragmentado e descontextualizado, em detrimento de uma formação disciplinar tradicional.

Todavia, do ponto de vista da gestão dos sistemas escolares, parece haver uma predileção pelos professores oriundos de formações disciplinares. Com relação à disciplina de Ciências, conforme já relatado, o licenciado em Biologia passou a ter a prerrogativa de lecioná-la no ensino fundamental. Com o passar do tempo, as secretarias de educação ratificaram essa prática, contratando professores licenciados em Biologia, por meio de concursos públicos e processos seletivos, para atuarem nessa disciplina (VILELA; BARTH; GOMES, 2017).

Isto posto, ao longo da história, foi se consolidando uma desconfiança acerca da qualidade da formação e do espaço de atuação profissional dos licenciados em Ciências Naturais/ da Natureza. Segundo Bierhalz, Araújo e Lima (2013), esse contexto acaba por tornar a formação desinteressante ao olhar de possíveis candidatos, visto que estes não conseguem enxergar com clareza quais serão as suas reais possibilidades de inserção profissional após conclusão do curso.

Magalhães Júnior e Pietrocola (2010), ao discutirem essa problemática, alertam que cursos de formação disciplinar, como é o caso da licenciatura em Biologia, formam professores que terão maiores dificuldades em trabalhar com a 


\title{
Authaดูã
}

ISSN: 1984-6444 | http://dx.doi.org/10.5902/1984644443625

disciplina de Ciências, dadas as suas características epistemológicas e metodológicas. Nesse segmento, Cunha e Krasilchik (2000, p. 2-3) argumentam:

\begin{abstract}
No que diz respeito às Licenciaturas em Ciências Biológicas, estejam elas vinculadas ou não aos Bacharelados, incluindo aqui também os cursos bem-conceituados, estão longe de formar adequadamente o professor de Ciências para o Ensino Fundamental, em vista de seus currículos altamente biologizados. Da mesma forma ocorre nos cursos de Licenciatura em Física e em Química, também pela concentração de disciplinas em suas áreas específicas. Insistir que os cursos de Biologia, Química ou Física priorizem a formação do professor de Ciências tem sido uma batalha para os formadores de professores, mas a prioridade nesses cursos não é esta, principalmente quando o curso apresenta também a modalidade de Bacharelado.
\end{abstract}

Do ponto de vista legal, não existem normas, diretrizes e/ou referenciais curriculares que definem qual curso de licenciatura apresenta uma proposta mais adequada para formar professores para ministrar a disciplina de Ciências nos anos finais do ensino fundamental. Destarte, por conta dessa lacuna legal, tem ficado a cargo das secretarias de educação, sobretudo dos estados, definir o perfil e a formação dos profissionais que atuarão nessas disciplinas em seus respectivos sistemas de ensino.

Os sistemas estaduais de ensino, conforme disposto no art. 10 da LDB de 1996, têm a autonomia para estabelecer critérios para a contratação de seu quadro de professores, desde que sejam obedecidas às normas estabelecidas na legislação educacional brasileira que tratam do tema (BRASIL, 2008). Compõem os sistemas estaduais dois órgãos superiores, que, atuando de modo articulado, são os responsáveis por gerir a educação nos estados, sendo eles: a Secretaria de Estado da Educação (SEDUC) e o Conselho Estadual de Educação (CEE). Estes órgãos possuem atribuições executivas e normativas, respectivamente (OLIVEIRA; SOUZA; CÂMARA, 2018).

Os Conselhos Estaduais, além de sua função normativa, também auxiliam as Secretarias de Educação, realizando atividades de assessoramento, fiscalização, controle, bem como na construção das políticas educacionais (BRASIL, 1996). Por conta dessas atribuições, os CEEs também emitem atos normativos e pareceres, 


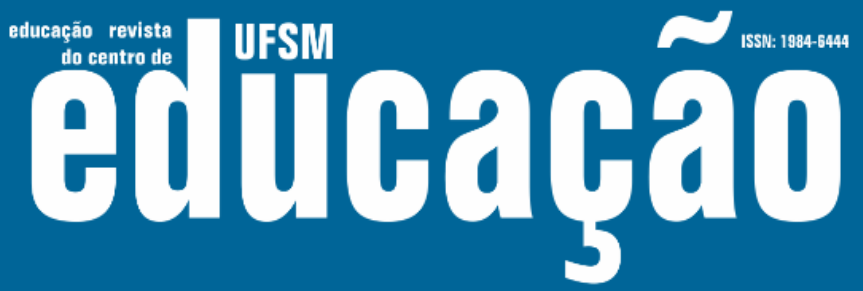

ISSN: 1984-6444 | http://dx.doi.org/10.5902/1984644443625

visando a orientar os órgãos que integram os sistemas de ensino sobre a qualificação necessária a ser exigida dos docentes, para que estes possam ministrar disciplinas ofertadas na educação básica.

\section{Percurso Metodológico}

A presente investigação caracteriza-se como uma pesquisa com abordagem qualitativa, de cunho exploratório e descritivo. Esse enquadramento metodológico deu-se com base nas ponderações de Creswell (2014, p. 49), quando diz que uma pesquisa qualitativa "consiste em um conjunto de práticas materiais interpretativas que tornam o mundo visível".

A partir da definição da abordagem metodológica da pesquisa, foram selecionadas as fontes e os procedimentos de investigação, visando à produção dos dados. Optamos, então, pelo levantamento bibliográfico e pesquisa documental.

O levantamento bibliográfico foi realizado com o intuito de compreender de que forma vem se constituindo as discussões sobre a formação de professores de Ciências para o ensino fundamental, em especial, aquelas que tratam dos espaços de atuação profissional dos licenciados em Ciências Naturais/da Natureza.

A produção dos dados também ocorreu por meio da pesquisa documental. De acordo com Sampieri, Collado e Lúcio (2013), essa é uma fonte muito rica de dados qualitativos. Os documentos investigados e analisados foram atos normativos, pareceres e demais escritos, emitidos pelos Conselhos Estaduais de Educação. Os documentos selecionados e estudados têm como finalidade orientar as Secretarias Estaduais de Educação sobre a formação inicial exigida dos docentes, para que estes possam ministrar a disciplina de Ciências nos anos finais do Ensino Fundamental.

O levantamento dos documentos foi realizado por meio de busca nos sites oficiais dos CEEs das 27 unidades da Federação. Para os conselhos que não disponibilizavam em sua página um repositório dos atos normativos, pareceres e documentos expedidos, foi realizado contato via e-mail e por telefone. $O$ trabalho de pesquisa e localização dos documentos ocorreu no período de março de 2018 a 


\section{Aillbapẫ

março de 2019.

\section{As manifestações e pareceres dos CEEs sobre a formação docente exigida para ensinar Ciências no ensino fundamental}

No período em estudo, dentre os 27 CEEs investigados, em 7 deles, foram localizados atos normativos, pareceres, escritos e/ou manifestações que versavam sobre a formação docente necessária para ministrar a disciplina de Ciências no ensino Fundamental. O Quadro 1 apresenta os documentos localizados, distribuídos de acordo com os estados que sediam esses conselhos.

Foram localizadas manifestações de CEEs distribuídas por todas as regiões do país. Importante dizer que não há como afirmar que os documentos que tratam do tema aqui investigado foram localizados em sua totalidade. Não existe um padrão entre os Conselhos quanto aos modos de divulgação de suas deliberações e pareceres. Além disso, alguns desses órgãos não mantêm um canal permanente de contato com a sociedade, não permitindo, dessa forma, obter informações e/ou esclarecimentos sobre suas ações, posicionamentos e decisões.

De forma geral, os documentos analisados demonstram que os CEEs têm posicionamentos que coadunam com o que dispõe o art. $62^{11}$ da LDBEN. Em outras palavras, há um consenso sobre a obrigatoriedade de que, para se atuar na educação básica, é obrigatório que os professores sejam formados em cursos de licenciatura.

As resoluções e deliberações dos CEEs sediados nos estados do Pará, Espírito Santo e Mato Grosso do Sul apenas reproduzem as disposições gerais previstas na LDBEN. Nesses documentos, cita-se apenas a obrigatoriedade de o professor ter uma licenciatura específica na área da disciplina que lecionará. Todavia, não preveem, especificamente, qual é a formação adequada para cada componente curricular, tampouco para a disciplina de Ciências. 


\section{$\sim$ ussm

ISSN: 1984-6444 | http://dx.doi.org/10.5902/1984644443625

preferência entre essas formações:

Art. $6^{\circ}$ - Para a concessão da autorização temporária ao exercício do magistério em qualquer das disciplinas abaixo relacionadas, deve ser observado um dos requisitos de qualificação, na ordem em que estão estabelecidos:

[...] VI - para o ensino de Ciências: portador de diploma de bacharelado em Biologia, portador de diploma do curso de Enfermagem, Medicina, Odontologia ou Fisioterapia, o aluno do curso de licenciatura em Ciências Naturais com, pelo menos $50 \%$ da carga horária integralizada; (PARAÍBA, 2008).

Apesar de se tratar de uma "concessão temporária", é importante ressaltar que os estados, em sua maioria, têm adotado a prática de realizar contratações temporárias de professores. Esses contratos "precários" têm substituído a realização de concursos públicos. Nesse segmento, Lima e Vasconcelos (2008) relatam que a falta de concursos para a renovação do quadro efetivo, na medida em que se amplia o quantitativo de alunos no ensino fundamental, acaba por contribuir com a carência de professores de Ciências, sobretudo, no Nordeste.

Dessa forma, sem que haja concurso público destinado ao provimento de vagas para professores efetivos, a tendência é que estes profissionais com formação bacharelesca permaneçam, indefinidamente, lecionando a disciplina de Ciências. Ainda sim, mesmo que haja uma cobrança posterior para a regularização do exercício da docência, bastará que esses façam uma complementação pedagógica.

Formações emergenciais para a docência, como a complementação pedagógica, além de reiterar o status de precariedade e aligeiramento da formação, tendem a desvalorizar ainda mais a profissão docente. Nesse segmento, torna-se uma política que desvaloriza aqueles profissionais que adentraram um curso de licenciatura, em busca de uma formação adequada. Especificamente para os licenciados em Ciências Naturais/da Natureza, esse contexto acaba gerando maior dificuldade de inserção profissional, o que torna essa formação ainda menos atrativa.

Para o CEE do Ceará, não foram localizados atos normativos e/ou pareceres 


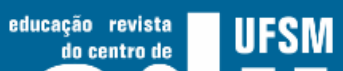 Autlbahat

ISSN: 1984-6444 | http://dx.doi.org/10.5902/1984644443625

que tratassem efetivamente do tema investigado neste estudo. No entanto, esse conselho publicou, no ano de 2008, um documento com perguntas e respostas, visando a dirimir dúvidas sobre a formação e qualificação dos docentes aptos a atuar nas disciplinas da educação básica. O "item 9" desse documento versava sobre a seguinte questão:

\section{9 - Licenciados em Ciências lotados na disciplina de Física. \\ $R$ - É aconselhável que se verifique o diploma, no título do curso e no apostilamento, para verificar a existência de estudos na área de Ciências da Natureza (Química, Física e Biologia). Nesse caso, é provável encontrar-se no histórico acadêmico alguns créditos com a finalidade conceitual para uma atuação docente na disciplina Física. (CEARÁ, 2008, p. 07).}

A situação casuística apresentada acima trata da possibilidade do licenciado em Ciências Naturais/da Natureza lecionar a disciplina de Física. Apesar do questionamento não se referir à atuação desse profissional no ensino fundamental, entendemos que o aconselhamento de se buscar o histórico do licenciando, para julgar se este está apto ou não a atuar na disciplina, denota a falta de uma posição mais clara sobre o real espaço de atuação desse profissional.

Autores como Barreyro et al. (2010), Magalhães Júnior e Pietrocola (2010), Bierhalz, Araújo e Lima (2013), Santos (2013), bem como Gozzi e Rodrigues (2017) já alertavam para indefinições quanto à atuação profissional desses licenciados, por conta da ausência de diretrizes e/ou referenciais curriculares específicos. Essas incertezas têm gerado pareceres ambíguos por parte dos órgãos educacionais, divergências que, muitas vezes, vão ser decididas no judiciário. Aliás, tem sido por meio de decisões judiciais ${ }^{12}$ que muitos dos licenciados em Ciências Naturais/da Natureza têm conseguido fazer valer o seu direito de lecionar na rede pública de ensino.

$\mathrm{O}$ ato normativo (Indicação CEE/SP n. ${ }^{\circ}$ 157/2016), expedido pelo CEE do estado de São Paulo, foi o único, dentre os documentos analisados, que efetivamente definiu a qualificação necessária para que o docente possa ministrar disciplinas na educação básica. A normativa define ainda que, a partir da sua publicação, todos os editais do sistema estadual de ensino, destinados à 


\section{Tism Autfarato

ISSN: 1984-6444 | http://dx.doi.org/10.5902/1984644443625

contratação de professores, deverão seguir os critérios de qualificação, classificação, assim como a ordem de prioridade nele definida.

Quanto à disciplina de Ciências, neste documento denominado de "Ciências Físicas e Biológicas", poderão ministrá-la os portadores dos seguintes diplomas:
a) Licenciatura em Ciências Biológicas;
b) Licenciatura em Biologia;
c) Licenciatura em História Natural;
d) Licenciatura em Ciências, com Habilitação em Biologia, Química, Matemática, Física;
e) Licenciatura em Ciências da Natureza;
f) Licenciatura em Ciências Exatas;
g) Licenciatura em Geociências e Educação Ambiental;
h) Licenciatura em Ciências Naturais, com Habilitação em Ciências;
i) Licenciatura em Educação do Campo com Habilitação em Ciências. (g.n.) (São Paulo, 2016).

Todos os licenciados nos cursos acima elencados são considerados como "Docentes Portadores de Curso Superior, licenciatura de graduação, com habilitação específica em área própria ou formação superior em área correspondente e complementação nos termos da legislação vigente, para provimento de cargo público" (SÃO PAULO, 2016). Em outras palavras, para a rede estadual de ensino paulista, são esses os licenciados que possuem formação adequada para ensinar Ciências nos anos finais do ensino fundamental.

Apesar do licenciado em Ciências da Natureza compor o rol de profissionais acima descrito, observa-se uma quantidade considerável de outros profissionais que também poderão lecionar a disciplina de Ciências. Dessa forma, percebemos que as necessidades de gestão do sistema educacional sobrepõe-se às finalidades pedagógicas da disciplina em questão. Se formos imaginar uma aula de Ciências ministrada por cada um desses profissionais, mesmo que seja de um mesmo conteúdo, o enfoque dado a este será totalmente diverso.

O ato normativo do CEE de São Paulo ainda prevê a possibilidade de atuação do licenciado em Ciências Naturais/da Natureza em disciplinas do ensino médio. De acordo com o documento, esse profissional poderá atuar nas disciplinas de Biologia, 


\section{Authaดูã}

ISSN: 1984-6444 | http://dx.doi.org/10.5902/1984644443625

Química e Física. Não é feita qualquer menção sobre a necessidade de uma habilitação específica para que ele possa atuar nessas disciplinas.

Apesar de haver a possibilidade de atuação do licenciado em Ciências Naturais/da Natureza em disciplinas do ensino médio, entendemos que a atuação nesse nível escolar deve estar condicionada ao que dispõe o perfil do egresso desses cursos. Para lecionar essas disciplinas, além do aprendizado dos conteúdos específicos, é primordial que o licenciado tenha tido uma formação pedagógica e uma prática profissional adequada a essa atuação. Caso contrário, será mais uma medida emergencial e precária, na tentativa de reverter o déficit de professores da área de Ciências da Natureza.

O Parecer n. 1 190/2010, emitido pela Câmara de Educação Superior do CEE do Paraná, também discutiu os limites de atuação profissional do licenciado em Ciências Naturais/da Natureza. O referido parecer teve como assunto principal o processo de renovação de reconhecimento do curso de licenciatura em Ciências, ofertado pela Universidade Estadual de Maringá (UEM), Campus Goierê.

De acordo com o Parecer, o curso de licenciatura em Ciências da UEM tinha como objetivo formar professores para lecionarem Ciências, no ensino fundamental, e ministrarem a disciplina Metodologia do Ensino de Ciências, no Ensino Médio. Todavia, no entendimento do CEE do Paraná, o licenciado em Ciências, egresso desse curso, só poderia atuar nos anos finais do ensino fundamental, visto que a atuação na disciplina de Metodologia do Ensino de Ciências seria prerrogativa do licenciado em Pedagogia. Como recomendação, o CEE indicou a necessidade de exclusão, no perfil do egresso, do item que dava a prerrogativa para que os licenciados nesses cursos pudessem atuar no ensino médio.

A segunda recomendação presente no parecer tratou da recomendação para que a UEM substituísse o curso de licenciatura em Ciências por uma licenciatura em Ciências Biológicas:

que proceda a alteração de seu Projeto Pedagógico do Curso de Graduação em Ciências - Licenciatura, para Curso de Graduação em Ciências Biológicas - Licenciatura, visto a inexistência de Diretrizes Curriculares Nacionais para o Curso, bem como o baixo número de alunos matriculados, conforme relato do Perito (fls. 225). (PARANÁ, 2010, p. 08). 


\section{Autนaดูลิ}

ISSN: 1984-6444 | http://dx.doi.org/10.5902/1984644443625

Ao recomendar a extinção do curso de licenciatura em Ciências e, em seu lugar, implantar o curso de licenciatura em Ciências Biológicas, é evidenciada a predileção por cursos de formação disciplinar, em detrimento daqueles que formam por área do conhecimento. Além disso, reafirma a prática histórica de conceder ao licenciado em Biologia a prerrogativa de lecionar Ciências no ensino fundamental.

Tendo como referência as reflexões de Magalhães Júnior (2007), Bierhalz, Araújo e Lima (2013), Canziani (2016), Gozzi e Rodrigues (2017), dentre outros, os argumentos utilizados para justificar a mudança na oferta do curso são recorrentes. A ausência de uma diretriz curricular, dentre outros problemas, tem gerado impasses na construção do currículo desses cursos, o que gera, por consequência, indefinições quanto ao perfil de seus egressos.

Imbernon et al. (2011), ao apresentar um panorama dos cursos de licenciatura em Ciências Naturais/da Natureza no Brasil, relata que, por conta da ausência dessas diretrizes, esses cursos foram implantados por diversas instituições, com os mais variados objetivos e arranjos curriculares.

Diante do cenário de incertezas apresentado, é evidente que os licenciandos do curso fiquem desmotivados quanto ao seu futuro profissional. Além de não haver uma clareza quanto ao espaço de atuação profissional desse licenciado, temos um contexto atual em que a carreira docente não é atraente.

Dessa forma, os candidatos a esses cursos acabam sendo pessoas que estavam há muito tempo sem estudar ou são aqueles que não conseguiram ingressar no curso que seria a sua primeira opção. Para esses indivíduos, o principal atrativo que os leva a ingressar na licenciatura em Ciências é a baixa concorrência nos processos seletivos. O resultado é que, por conta da desmotivação com a carreira docente, da falta de identificação com o curso e pelo próprio grau de dificuldade enfrentado ao cursar as disciplinas, a tendência é que haja um alto índice de evasão. 


\section{Autharẫ}

ISSN: 1984-6444 | http://dx.doi.org/10.5902/1984644443625

\section{Considerações finais}

Os estudos realizados nesta investigação convergem para revelar que as políticas voltadas à formação de professores de Ciências no Brasil ocorreram sempre na tentativa de reverter um déficit quantitativo desses professores para a educação básica. Para os sistemas estaduais de ensino, em que foram obtidos posicionamentos dos CEEs sobre a problemática aqui investigada, observou-se que existe um rol de licenciados considerados como aptos para lecionar a disciplina de Ciências.

Essa relação é composta por professores oriundos de licenciaturas disciplinares em Biologia, Química e Física, incluindo-se também os licenciados em Ciências Naturais/da Natureza. Importante dizer que não há uma definição por parte desses sistemas de ensino de qual dessas formações seria a mais adequada para 0 professor que leciona a disciplina de Ciências no ensino fundamental.

Entendemos que a definição de uma relação de profissionais considerados como habilitados para lecionar a disciplina de Ciências reflete a prioridade dos sistemas de ensino no atendimento de suas demandas operacionais e de gestão. Nessa perspectiva, torna-se uma medida rápida e barata, na tentativa de reverter 0 déficit de professores com formação adequada para área de Ciências da Natureza.

A prioridade dada pelos sistemas de ensino às suas necessidades de gestão, em detrimento das necessidades formativas da disciplina de Ciências, acaba por dificultar a inserção profissional dos licenciados em Ciências Naturais/da Natureza. Nessa perspectiva, o professor a ser contratado será sempre aquele habilitado a ministrar o maior número possível de disciplinas, por consequência, a contratação do licenciado em Ciências Naturais/da Natureza, que, na maioria dos casos, só está habilitado para atuar nos anos finais do ensino fundamental, não seria viável.

O fato de o curso não possuir diretrizes e/ou referenciais curriculares específicos também é um outro obstáculo à inserção profissional desses licenciados. $\mathrm{Na}$ ausência dessas normas, as definições sobre o seu campo de atuação ficam a mercê de pareceres isolados e esparsos. Esses documentos seriam importantes no 


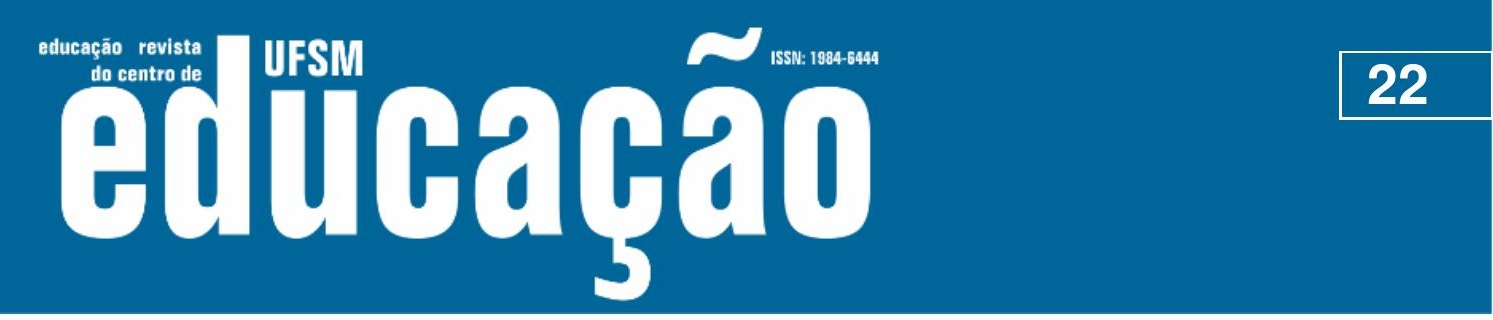

ISSN: 1984-6444 | http://dx.doi.org/10.5902/1984644443625

sentido de demarcar o espaço de atuação desses professores, dirimindo, assim, quaisquer dúvidas ou questionamentos dos sistemas de ensino.

Diante do contexto investigado, podemos inferir que o licenciado em Ciências Naturais/da Natureza terá que continuar disputando o seu espaço de atuação profissional com as demais licenciaturas disciplinares, em especial, a licenciatura em Ciências Biológicas. Além disso, por conta dos posicionamentos dos CEEs conhecidos neste estudo, essa disputa nem sempre será equilibrada. Apesar de ter uma formação que coaduna com as finalidades formativas da disciplina de Ciências, nem sempre essa será a prioridade dos sistemas estaduais de ensino.

\section{Referências}

AULER, Décio. Enfoque Ciência - Tecnologia - Sociedade: Pressupostos para o conexto brasileiro. Ciência \& Ensino, v. 1, n. Esp., p. 1-20, 2007.

BARREYRO, Gladys Beatriz et al. Uma proposta inovadora de estágios para os professores de Ciências: A experiência do curso de licenciatura em Ciências da Natureza (EACH-USP) em São Paulo, Brasil. Experiências em Ensino de Ciências, Porto Alegre, v. 5, n. 3, p. 83-93, 2010. Disponível em: http://www.if.ufrgs.br/eenci/artigos/Artigo_ID123/v5_n3_a2010.pdf. Acesso em: 12 mai. 2020.

BIERHALZ, Daniela Crisna Krause, ARAÚJO, Rafaele Rodrigues de, LIMA, Viviane de Almeida. Licenciatura Interdisciplinar em Ciências da Natureza - análise do Projeto Pedagógico do Curso. In: SIMPÓSIO INTERNACIONAL SOBRE INTERDISCIPLINARIDADE NO ENSINO, NA PESQUISA E NA EXTENSÃO. 2013, Santa Catarina. Anais...Santa Catarina/SC. Disponível em: http://www.siiepe.ufsc.br/wp-content/uploads/2013/10/A-Bierhalz.pdf. Acesso em: 05 mai. 2020.

BRASIL. Base Nacional Comum Curricular (Educação Infantil e Ensino Fundamental). Brasilia: Ministério da Educação, 2017. Disponível em: http://basenacionalcomum.mec.gov.br/wp-content/uploads/2018/02/bncc-20dezsite.pdf. Acesso em: 13 jun. 2018.

BRASIL. Lei de Diretrizes e bases da educação nacional. Lei $n^{\circ} 9.394$, de 20 de dezembro de 1996, 1996. Disponível em: http://www.planalto.gov.br/ccivil_03/leis/L9394.htm. Acesso em: 20 jan. 2017 


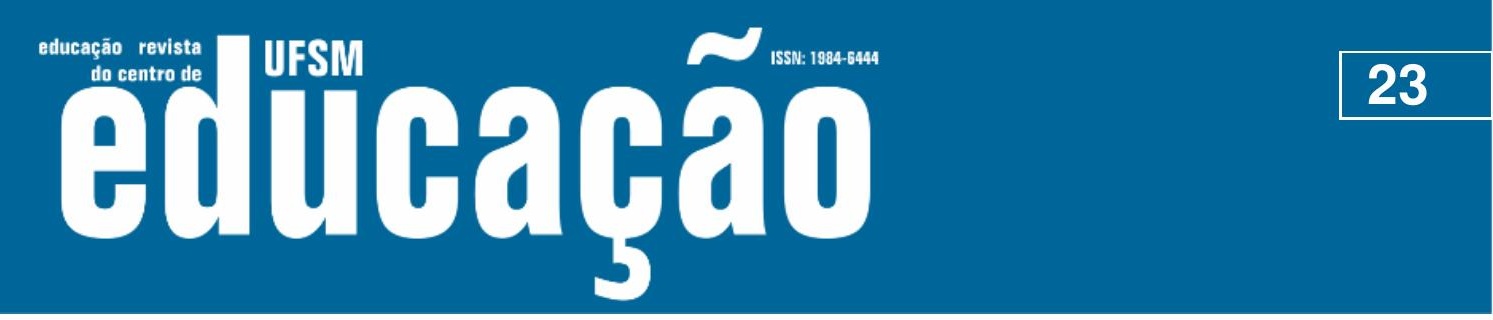

ISSN: 1984-6444 | http://dx.doi.org/10.5902/1984644443625

BRASIL. Parâmetros Curriculares Nacionais - $3^{\circ}$ e $4^{\circ}$ ciclos do Ensino Fundamental (vol. 1 - Introdução). Brasília: Ministério da Educação, 1998. Disponível em: http://portal.mec.gov.br/par/195-secretarias-112877938/sebeducacao-basica-2007048997/12657-parametros-curriculares-nacionais-5o-a-8oseries. Acesso em: 22 mai. 2020.

BRASIL. Parecer CNE/CP n 25/2002MEC/Conselho Nacional de Educação, 2002. Disponível em: http://portal.mec.gov.br/cne/arquivos/pdf/cp252002.pdf. Acesso em: 19 mar. 2020

BRASIL. Parecer CNE/CES n 54/2008Brasília CNE/MEC, , 2008. Disponível em: http://portal.mec.gov.br/cne/arquivos/pdf/2008/pces054_08.pdf. Acesso em: 22 mar. 2020

CACHAPUZ, Antonio et al. A necessária renovação para o ensino de Ciências. São Paulo: Cortez, 2005.

CANZIANI, Tatiana de Medeiros. Análise da perspectiva integrada do currículo flexibilizado na licenciatura em ciências da Universidade Federal do Paraná setor litoral. 2015. 250 f. Tese (Doutorado em Educação) - Faculdade de Educação, Universidade de São Paulo, São Paulo, 2015. Disponível em: https://www.teses.usp.br/teses/disponiveis/48/48134/tde-09032016-151119/ptbr.php. Acesso em: 02 mai. 2020.

CARVALHO, Anna Maria Pessoa de. Formação de professores de ciências tendencias e inovações. 10ª ed. São Paulo: Cortez, 2000.

CEARÁ. Perguntas e respostas sobre autorização temporária e outros temas correlatosFortalezaCEE/Ceará, , 2008.2 Disponível em: https://www.cee.ce.gov.br/wp-content/uploads/sites/49/2018/06/perguntas-erespostas-cee-versao-corrigida-03.07.2008.pdf. Acesso em: 22 mar. 2020

CHASSOT, Attico. Alfabetização científica: questões e desafios para a educação. 4. ed. ljuí: Unijuí, 2006.

CRESWELL, John W. Insvestigação qualitativa e projeto de pesquisa. 3. ed. Porto Alegre: Penso, 2014.

CUNHA, Ana Maria de Oliveira; KRASILCHIK, Myriam. A formação continuada de professores de Ciências: percepções a a partir de uma experiência. 23a REUNIÃO DA ASSOCIAÇÃO NACIONAL DE PÓS GRADUAÇÃO E PESQUISA EM EDUCAÇÃO. 2000. Caxambu. Anais...Caxambú: ANPED. Disponível em: http://23reuniao.anped.org.br/textos/0812t.PDF. Acesso em: 17 maio. 2017. 


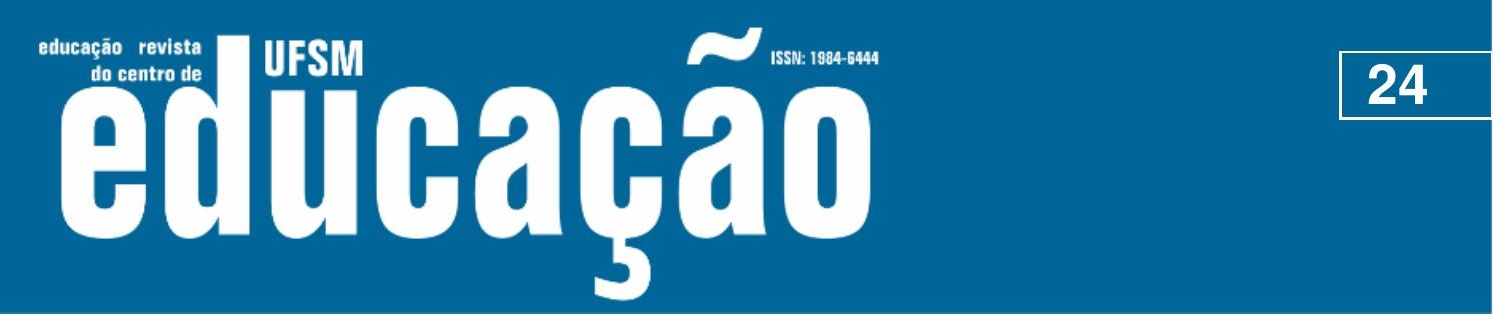

ISSN: 1984-6444 | http://dx.doi.org/10.5902/1984644443625

FERREIRA, Eunice Freitas. Licenciatura de curta duração: solução emergencial ou definitiva? Sitientibus, Feira de Santana, v. 2, n. 3, p. 155-163, 1983. Disponível em: http://www2.uefs.br/sitientibus/pdf/3/lincenciatura_de_curta_duracao.pdf. Acesso em: 02 fev. 2020.

FRANCO, Luiz Gustavo, MUNFORD, Danusa. Reflexões sobre a Base Nacional Comum Curricular: Um olhar da área de Ciências da Natureza. Horizontes, v. 36, n. 1, p. 158-171, 2018. Disponível em: https://revistahorizontes.usf.edu.br/horizontes/article/view/582. Acesso em: 23 abr. 2020.

GOMES, Magno. Delimitação de atribuições educacionais: sistemas de ensino e competência constitucional. Revista Brasileira de Estudos Pedagógicos, Brasília, v. $92, \quad$ n. 230, p. 166-186, 2011. Disponível em: http://rbep.inep.gov.br/ojs3/index.php/rbep/article/view/2926. Acesso em: 19 fev. 2020.

GOZZI, Maria Estela; RODRIGUES, Maria Aparecida. Características da Formação de Professores de Ciências Naturais. Revista Brasileira de Pesquisa em Educação em Ciências, v. 17, n. 2, p. 423-449, 2017. Disponível em: https://periodicos.ufmg.br/index.php/rbpec/article/view/4455. Acesso em: 02 mar. 2020.

IMBERNON, Rosely Aparecida Liguori et al. Um panorama dos cursos de licenciatura em ciências naturais (LCN) no Brasil a partir do $2^{\circ}$ Seminário Brasileiro de Integração de Cursos de LCN/2010. Experiências em Ensino de Ciências, Cuiabá, v. 6, n. 1, p. 85-93, 2011. Disponível em: http://if.ufmt.br/eenci/artigos/Artigo_ID134/v6_n1_a2011.pdf. Acesso em: 02 fev. 2020.

KRASILCHIK, Myriam. Reformas e realidade: o caso do ensino das ciências. São Paulo em Perspectiva, v. 14, n. 1, p. 85-93, 2000. Disponível em: http://www.scielo.br/pdf/spp/v14n1/9805.pdf. Acesso em: 02 fev. 2020.

LIMA, Kenio Erithon Cavalcante; VASCONCELOS, Simão Dias. O professor de Ciências das Escolas Municipais de Recife e suas perspectivas de educação permanente. Ciência \& Educação (Bauru), São Paulo, v. 14, n. 2, p. 347-364, 2008. Disponível em:

http://www.scielo.br/scielo.php?pid=S15163132008000200012\&script=sci_abstract\&t Ing=es. Acesso em: 05 mai. 2020.

MAGALHÃES JÚNIOR, Carlos Alberto de Oliveira; PIETROCOLA, Maurício. A formação dos professores de Ciências para o Ensino Fundamental. In: SIMPÓSIO NACIONAL DO ENSINO DE FÍSICA, 16, 2005, Rio de Janeiro. Anais...Rio de Janeiro: SBF, 2005. 


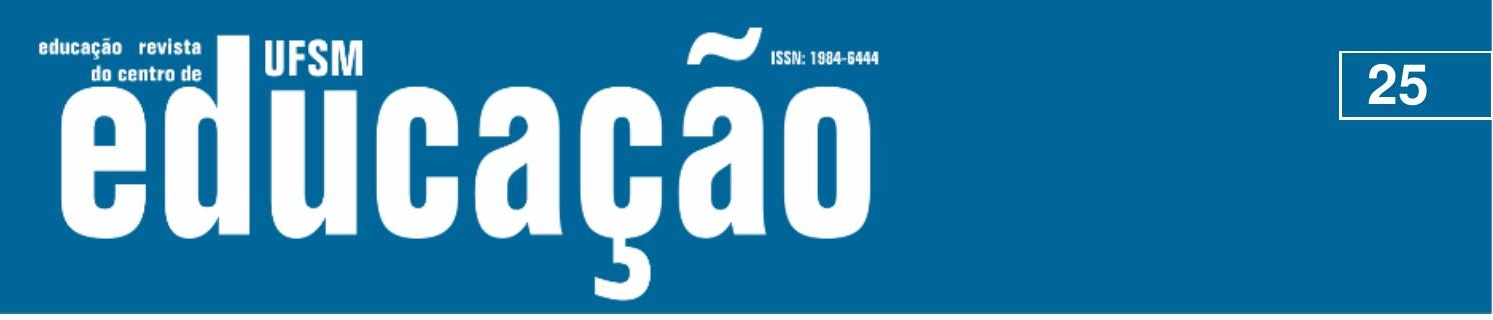

ISSN: 1984-6444 | http://dx.doi.org/10.5902/1984644443625

MAGALHÃES JÚNIOR, Carlos Alberto de Oliveira; PIETROCOLA, Maurício. Análise de propostas para a formação de professores de Ciências do ensino fundamental. Alexandria: Revista de Educação em Ciência e Tecnologia, Florianópolis, v. 3, n. 2, p. 31-58, 2010. Disponível em: https://periodicos.ufsc.br/index.php/alexandria/article/view/38098. Acesso em: 05 mai. 2020.

MAGALHÃES JÚNIOR, Carlos Alberto de Oliveira; PIETROCOLA, Mauricio. O currículo e a formação de professores de ciências do ensino fundamental dos Estados do Paraná e São Paulo. 2007.Tese (Doutorado). Universidade de São Paulo, São Paulo, $2007 . \quad$ Disponível em: https://repositorio.usp.br/single.php?_id=001653964. Acesso em: 05 mai. 2020.

NASCIMENTO, Fabrício do; FERNANDES, Hylio Laganá; DE MENDONÇA, Viviane Melo de. O ensino de ciências no Brasil: história, formação de professores e desafios atuais. Revista HISTEDBR On-line, Campinas, v. 10, n. 39, p. 225-249, $2010 . \quad$ Disponível em: https://periodicos.sbu.unicamp.br/ojs/index.php/histedbr/article/view/8639728.

Acesso em: 15 abr. 2020.

NASCIMENTO, Thiago Rodrigues. A criação das licenciaturas curtas no Brasil. Revista HISTEDBR On-line, Campinas, n. 45, p. 340-346, 2012. Disponível em: http://www.histedbr.fe.unicamp.br/revista/edicoes/45/doc01_45.pdf. Acesso em: 05 mai. 2020.

OLIVEIRA, Rosimar de Fátima; SOUZA, Donaldo Bello; CÂMARA, Adriane Peixoto. Conselhos Estaduais de Educação nos Novos Planos Estaduais de Educação. Educação \& Realidade, Porto Alegre, v. 43, n. 2, p. 669-690, 2018. Disponível em: http://www.scielo.br/scielo.php?script=sci_arttext\&pid=S217562362018000200669.

Acesso em: 12 mai. 2020.

PARAÍBA. Resolução $n^{\circ}$ 101/2008. Estabelece competência e fixa normas para a concessão de autorização temporária ao exercício do magistério, no ensino fundamental e no ensino médio, nas unidades de ensino que compõem o sistema estadual de ensino.CEE/PB, 2008. Disponível em: https://www.cee.pb.gov.br/wpcontent/uploads/2015/07/Re101-2008-Normativa-Normas-para-a-concessao-paraexercicio-do-magisterio.pdf. Acesso em: 22 mar. 2020.

PARANÁ. Parecer $n^{\circ}$ 190/2010. Renovação do Reconhecimento do Curso de Graduação em Ciências - Licenciatura - Campus de Goioerê.CuritibaCEE/Paraná, , 2010.

Disponível

em: http://www.cee.pr.gov.br/arquivos/File/pdf/Pareceres2010/CES/pa_ces_190_10.pdf. Acesso em: 22 mar. 2020.

SAMPIERI, Roberto Hernández; COLLADO, Carlos Fernández; LUCIO, María Del Pilar Baptista. Metolodogia de Pesquisa. 5. ed. ed. Porto Alegre: Penso, 2013. 


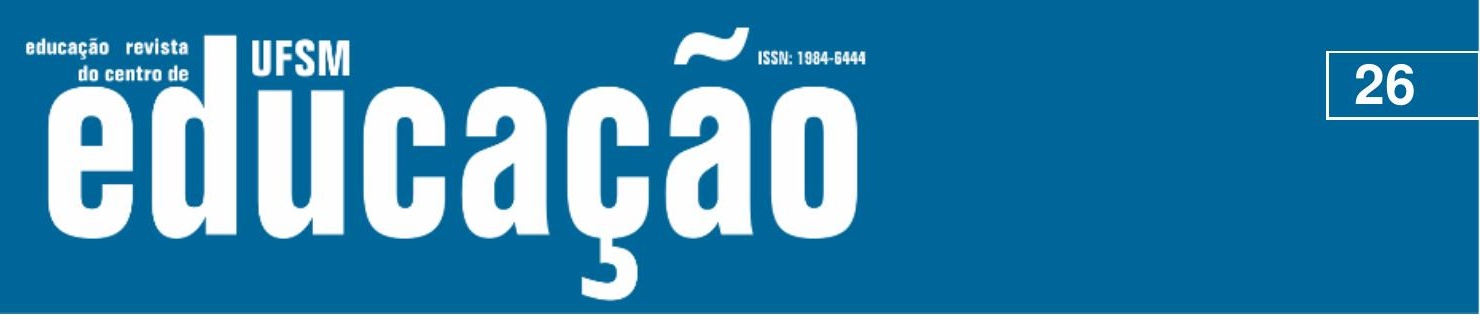

ISSN: 1984-6444 | http://dx.doi.org/10.5902/1984644443625

SANTOS, Saulo Cézar Seiffert. Reflexões do $2^{\circ}$ Encontro Nacional dos estudantes de ciências: possibilidades e avanços curriculares. In: III SIMPOSIO DE EDUCAÇÃO DE CIÊNCIAS DA AMAZÔNIA, Manaus, 2013. Anais...Manaus: III Simposio de Educação de Ciências da Amazônia, 2013.

SANTOS, Widson Luiz Pereira. Significados da educação científica com enfoque CTS. In: SANTOS, Widson Luiz Pereira; AULER, Décio (Orgs.). (Eds.). CTS e Educação Científica: Desafios, Tendências e Resultados de Pesquisas. Brasilia: Editora UnB, 2011. p. 21-48.

SÃO PAULO. Indicação CEE n` 157/2016. Orientação ao Sistema Estadual de Ensino a respeito da qualificação necessária dos docentes para ministrarem aulas nas disciplinas do currículo da Educação Básica.CEE/SP, 2016. Disponível em: http://siau.edunet.sp.gov.br/ItemLise/arquivos/RESOLUÇÃO DE 26-122016. HTM?Time=01/02/2018 14:50:18. Acesso em: 22 mar. 2020.

SILVA, Rejane Conceição Silveira; PEREIRA, Elaine Corrêa. Currículos de ciências: uma abordagem histórico- cultural. Atas do VIII ENCONTRO NACIONAL DE PESQUISA EM EDUCAÇÃO EM CIÊNCIAS - VIII ENPEC, Campinas, 2011. Anais...Campinas: ABRAPEC, 2011. Disponível em: http://www.nutes.ufrj.br/abrapec/viiienpec/resumos/R0836-1.pdf. Acesso em: 12 abr. 2018.

TENFEN, Danielle Nicolodelli. Editorial: Base Nacional Comum Curricular (BNCC). Caderno Brasileiro de Ensino de Física, Florianópolis, v. 33, n. 1, p. 1, 2016. Disponível em: https://periodicos.ufsc.br/index.php/fisica/article/view/21757941.2016v33n1p1. Acesso em: 05 mai. 2020.

ULIANA, Edna Regina. Histórico do curso de Ciências Biológicas no Brasil e em Mato Grosso. In: VI COLÓQUIO INTERNACIONAL "EDUCAÇÃO E CONTEMPORANEIDADE", São Cristóvão, 2012. Anais...São Cristovão: Grupo de Pesquisa Educação e Contemporaneidade (EDUCON/CNPq/UFS), 2012. Disponível em: http://educonse.com.br/2012/eixo_06/PDF/34.pdf. Acesso em: 05 mai. 2020.

VILELA, Marcos Vinícius Ferreira. A interdisciplinaridade e a abordagem Ciência, Tecnologia, Sociedade e Ambiente (CTSA), em três cursos de licenciatura em Ciências Naturais/da Natureza ofertadas por instituições sediadas na Amazônia Legal. 2018. Tese (Doutorado). Universidade Federal de Mato Grosso, 2018.

VILELA, Marcos Vinícius Ferreira; BARTH, Adriane; GOMES, Marcio do Nascimento. O lugar do licenciado em Ciências Naturais/da Natureza na educação básica brasileira: uma análise a partir dos editais de concursos públicos. Revista Prática Docente, Confresa, v. 2, n. 1, p. 48, 8 jul. 2017. Disponível em: http://periodicos.cfs.ifmt.edu.br/periodicos/index.php/rpd/article/view/57. Acesso em: 05 mai. 2020. 


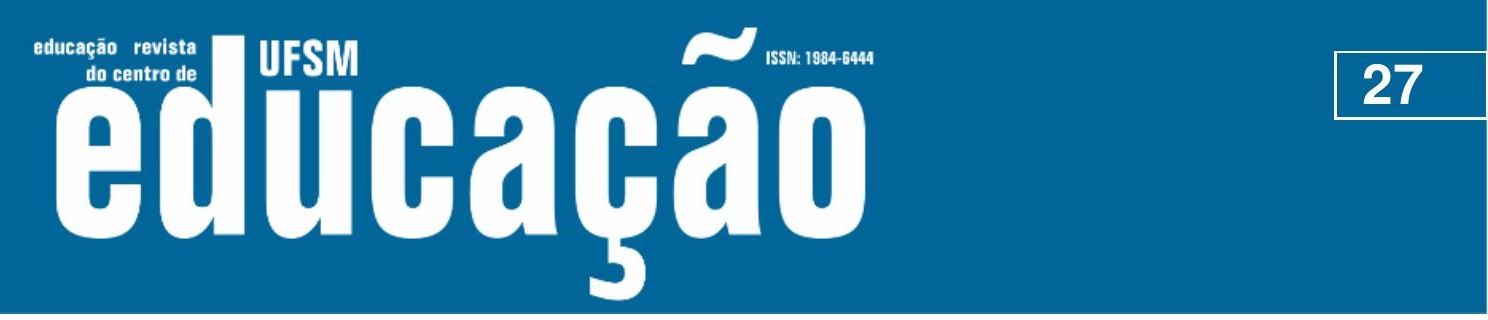

ISSN: 1984-6444 | http://dx.doi.org/10.5902/1984644443625

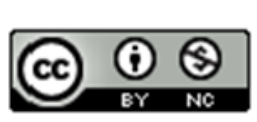

This work is licensed under a Creative Commons Attribution-NonCommercial 4.0 International (CC BY-NC 4.0)

\section{Notas}

\footnotetext{
${ }^{1}$ Lei de Diretrizes e Bases da Educação Nacional (Lei n’ 9.394/1996).

2 A denominação "Ciências Naturais/da Natureza" é usada neste trabalho para se referir aos diferentes cursos de licenciatura que formam professores para a área do conhecimento de Ciências da Natureza. Os professores formados nesses cursos são habilitados para lecionar a disciplina de Ciências nas séries finais do ensino fundamental.
}

${ }^{3}$ Lei n. ${ }^{\circ}$ 5.692, de 11 de agosto de 1971 - Fixa Diretrizes e Bases para o ensino de $1^{\circ}$ e $2^{\circ}$ graus e dá outras providências

4 Neste trabalho, entendemos por alfabetização Científica o "conjunto de conhecimentos que facilitariam aos homens e mulheres fazer uma leitura do mundo onde vivem" (CHASSOT, 2006, p. 19).

5 Lei n.ํ 9.394, de 20 de dezembro de 1996 - Estabelece as Diretrizes e Bases da educação nacional.

${ }^{6}$ Documento de caráter normativo que define o conjunto orgânico e progressivo de aprendizagens essenciais que todos os alunos devem desenvolver ao longo das etapas e modalidades da Educação Básica (BRASIL, 2017, p. 07).

7 [...] em matéria educacional, o sistema é composto pelo conjunto de instituições, com seus elementos materiais e pessoais, e pelo ordenamento jurídico federal e estadual, o que se denomina sistema de ensino ou sistema de educação (GOMES, 2011, p. 177) .

${ }^{8}$ [...] aqui entendidos como conteúdos, conceitos e processos - que, por sua vez, são organizados em unidades temáticas (BRASIL, 2017, p. 28).

${ }^{9}$ Conselho Federal de Educação.

10 Programa de Reestruturação e Expansão das Universidades Federais.

11 Art. 62. A formação de docentes para atuar na educação básica far-se-á em nível superior, em curso de licenciatura, de graduação plena, em universidades e institutos superiores de educação, admitida, como formação mínima para o exercício do magistério na educação infantil e nos 5 (cinco) primeiros anos do ensino fundamental, a oferecida em nível médio na modalidade normal. (Redação dada pela Lei no 12.796, de 2013) (BRASIL, 1996).

12 Exemplo de decisão judicial sobre o tema:

EMENTA: Mandado de Segurança - Concurso público - Professor da rede estadual - Exigência de formação com licenciatura plena em Ciências Biológicas, Física e Química. Impetrante com formação em Ciências Naturais - Anulada Resolução que reconheceu a correlação entre as áreas de conhecimento Ciências Naturais, Biologia, Química e Física. Ato administrativo editado por autoridade incompetente - Ineficácia desde a sua edição - Efeitos inexistentes - Competência exclusiva da União para baixar normas sobre cursos de graduação e pós-graduação. (TJ-SE-MS: 0003771962012825000, Relatora: Maria Aparecida Santos Gama da Silva, Data de julgamento: 03/10/2012, TRIBUNAL PLENO). 